Journal of Social Sciences 7 (1): 90-99, 2011

ISSN 1549-3652

(C) 2010 Science Publications

\title{
Sustainability Education-A Challenge for South-East Asia and Europe
}

\author{
${ }^{1}$ Renate Kärchner-Ober and ${ }^{2}$ Uwe Dippel \\ ${ }^{1}$ Department of Foreign Languages, Faculty of Modern Languages and Communication, \\ University Putra Malaysia, 43400 UPM Serdang, Selangor Malaysia \\ ${ }^{2}$ Department of Systems and Networking, College of Information Technology, \\ University Tenaga Nasional Km 7, Jalan Ikram-Uniten, 43009 Kajang, Selangor, Malaysia
}

\begin{abstract}
Problem statement: South-East Asia and Europe face rapid changes in social, economical and political terms. Though starting points are different, both regions experience similar problems. We see a strong slowdown of economic growth; changing proportions of the population through migration, natural disasters, economic reasons and aging populations. Problems and conflicts occur in the first decade of the new millennium, as a lot of changes in the educational sector have been undertaken. This study deals with sustainability education in both regions. Approach: In particular, we compare issues of higher education in Malaysia and Germany. We explore current tendencies and changes from various perspectives and how they fit into a concept of sustainability education. (Or is it education to sustainability, respectively sustainable education?) Results: It is shown, that sustainability in the educational field is possible only, if related to a socio-cultural context that considers the disposition of the individual; instead of using assumptions gathered and subsequently transferred from a society distinct in its predominant descriptors, respectively from determinators of some abstract industrial process demands. Conclusion: Sustainable education is recognized as a not a priori transferable entity in the global context. It must rather be contextualized and suitably embedded into individual and divers societal environs.
\end{abstract}

Key words: Sustainability education, curriculum development, higher education, global market, Malaysian Qualifications Framework (MQF), sustainable learning, economic growth

\section{INTRODUCTION}

South-East Asia and Europe face rapid changes in social, economical and political terms. Though starting points are different, both regions experience similar problems. On one side we see a strong slowdown of economic growth; changing proportions of the population through migration, natural disasters, economic reasons and aging populations. On the other side we see drastic changes in the field of education. However, the demographic transitions and population patterns have yet to be taken into account here, aside of only marginally. Doubtless, the resulting challenges have a strong effect on institutions of higher learning and schools, on curricula and subject areas. Students of all educational institutions, as well as teachers, education policy makers and parents are dealing with ongoing changes. Problems and conflicts occur in the first decade of the new millennium, as a lot of changes in the educational sector have been undertaken. However, there are many critics in both regions, from different points of view.
This study deals with sustainability education in both regions; in particular we compare issues of higher education in Malaysia and Germany. State education frameworks will be analyzed by discussing current curricular issues. Offering in-depth answers is not in the scope of this study, rather to explore current tendencies and changes from various perspectives and how they fit into a concept of sustainability education. (Or is it education to sustainability, respectively sustainable education?)

In the light of concrete issues in the field of higher education, we discuss the topic from a comparative perspective with a focus on Germany and Malaysia.

Questions like the following will be raised:

- Are subject areas of curricula still compartmentalized, or do they provide a framework for sustainability education?

- Are students encouraged to discuss questions, do carry out research interdisciplinary?

Corresponding Author: Renate Kärchner-Ober, Department of Foreign Languages, Faculty of Modern Languages and Communication, University Putra Malaysia, 43400 UPM Serdang, Selangor Malaysia 
- Do current curricula provide a platform to encourage students to create broad ways of thinking and critical attitudes towards society, political visions, consumer information, lifelong learning, environmental issues and sustainability?

When it comes to curriculum planning, ideological, pragmatic and instrumental arguments come into play. Current frameworks clearly focus on market forces, economic demands of the society, touching language issues as well.

Background: Students of today's world face a life of tremendous shifts in the light of globalisation, environmental issues, political instabilities, demographic changes and an increasing population in particular in third world countries alongside a decline of the number of children in the developed world. The last four decades have been a period of ongoing transformation. They are characterized by migration and transcontinental migration, economic shifts, uncomfortable political tensions, changes in societies and an explosion of information and communications technologies. One of the big questions, constantly and vehemently discussed and yet to be answered is, how to place education in any society of the 21st century, which is no static unit, but changes with more speed and power as ever known before.

Globally, Higher Education "has become, over the last century, one of the few truly global industries", as Wolf (2002) puts it. Educational systems and curricula assimilate worldwide regardless the particularities of a nation. However, Mufwene (2008) argues that "Mc Donald menu is partly adapted to the local diet" and thus homogenisation does not take place. On the other side, the maintenance of cultural (and linguistic) diversity comes under threat due to globalisation processes, which also results in a threat to maintain biodiversity. From an ecological view, the strongest ecosystems are those that are the most divers (Baker 2001). To use this analogy, current directions and concepts of university structures and curricula are not really devoted to diversity and sustainability in a broader sense, as a tendency to relate education and economy is increasing. Spring (2007) uses the term human capital approach in education for "the purpose of education as economic growth and preparing students for jobs" (ibid. 64). A most recent study carried out with third year undergraduates by one of the authors indicates that students classify jobs as medical doctor, lawyer, engineer and pilot as 'valuable' for a future society but low skills job such as car-mechanics or bus-driver as 'negative' for the development of the country's future. We may provokingly ask: "And who will clean roads and buildings and who will keep up the public transport?" (for a critical analysis, see Waldinger and Lichter, 2003).

Whether globalisation leads to homogenisation or not, we can clearly observe some central effects of elimination of diversity related to higher education. "Why should we study abroad when we follow an international standardized curriculum”, Dr. X, professor and Dean in a German university asks. A general trend shows an increasing enrolment of students in higher education and countries like Malaysia and Germany aim to further increase the numbers of degree-holders. Wolf (2002) criticizes that normal curves disappear and discusses the would-be scenario that "everyone has a degree", rooted in the "hype about the knowledge economy", ignoring the fact that unskilled jobs are "a pretty stable part of the employment scene” (ibid). Instead of creating a solid basis for a sustainable education and education for all, new separating lines are created and problems are postponed when it comes to employment opportunities. It is now apparent that the purpose of education (Bildung) or "intellectual flow" (Spring, 2007) has shifted towards human capital principles with the goal to prepare students for the job market. Students are becoming human capital and current directions of education neither create an environment of a freedom of thinking, nor do they prepare students to become independent, confident or critical thinkers. Employers and industry alike complain about graduates who do not possess skills beyond those tested in exams (if so), while at the same time, the industry forces universities to increase the number of graduates. One of the buzzwords is k-economy, which is defined by the OECD as an economy which is directly based on production, distribution and use of knowledge and information. Accordingly, all sectors of education are affected by this, as it is attempted to generate highly skilled professionals, leading to a "culture of measurements" and a "whole area of quality control” as Maley (2007) puts it. Implementing ISO 9001 in academic settings is said to guarantee quality. Knowledge is 'poured' into learners, the outcomes are measured and examinations are dominating the further progress. Ironically, or sadly, this is criticized by many Malaysian educators and scholars, just to quote Koo (2008) who states that "knowledge [is transmitted] principally in terms of learning a fixed body of information which can be regurgitated and applied without much comment in critique”. Standardisation in all subjects breeds a culture of testing and assessing, 
that is perceived by a number of authors to highly contradict (m)any forms of sustainable learning. Bentley (1998) uses the term 'machine like' education and argues: "It must be said that thinking in machinelike terms can be highly appropriate. Where external conditions are stable and predictable and the output have [sic!] been clearly defined, machine systems have proved very efficient”. Current educational practices, the mania of standardization, relate to this metaphor. Even common sense tells us, that societies and systems in the 21st century are anything but stable.

In sustainable learning, one of the main focuses lies on multi-strand approaches and changing roles of teachers and students; away from compartmentalized teaching and relating subjects within one singular topic. In our view, sustainable education also means to create a learning environment, based on relevant curricula, that makes students understand processes and how things are interrelated with each other. Without doubt, this cannot be measured directly.

On the other side, as testing and assessing increases, measurements are undertaken to assess quality. Learning modules and "measurable learning outcomes” (John Daniel, Assistant Director-General for Education, UNESCO) have become fashionable to ensure that a particular subject has been 'mastered'. Reforms suggested by the European Commission are as follows:

- Curricular reform: The three cycle system (bachelor-master-doctorate), competence based learning, flexible learning paths, recognition, mobility

- $\quad$ Governance reform: University autonomy, strategic partnerships, including with enterprises, quality assurance.

- $\quad$ Funding reform: Diversified sources of university income better linked to performance, promoting equity access and efficiency, including the possible role of tuition fees, grants and loans

The necessity to enhance curricular and pedagogical development in an increasingly globalised world seems to be obvious. We may also not forget, that in many parts of the world yet a basic and continuous education lacks.

Objectives: In this study, our objective will be, to cast a light on this scenario of the diversity-if not contradiction-of individualisation of learning and the streamlining process of standardisation in the realms of quality assurances. We will do this for two exemplary target areas: the higher education in Malaysia and Germany.
Processes: Current discussions concerning globalisation are centred around educational policies, economic and ecological issues, diversity of languages and more recently developments of sustainability in education. Concepts of sustainable development have advanced since the 1980s. In the 21st century, the discourse is related to globalisation processes and the era of information technology. In principle, sustainable development refers to the idea that a balance between society, environment and economy has to be achieved and maintained (Brundtland, 1987). Educational settings play a crucial role in approaching sustainability as a key element of education, thus, holistic approaches of teaching throughout subjects conceptualize this idea. Continuous learning and lifelong (academic) learning programmes are offered at higher institutions of learning, including the changing role of instructor/student, learning strategies, coping with new technologies, materials and refinements of course contents.

The question arises, how far this more holistic perspective on sustainability of education as deemed necessary, goes along well with rather rigid procedures of a more formalistic nature at so-called Quality Assurances, Qualification Frameworks, assessment, measurement, evaluation, targets, standards, exams, results, objectives (Maley, 2007). Recently, significant developments of educational programmes highlight the importance of efficiency, quality management, evaluation of curricula and a repertoire of buzzwords like human capital, marketability, evaluation, transparency, employability receives more attention in curricular designs in Europe and elsewhere. Curriculum planners, politicians and educators have used the lens outside the pedagogical world in order to establish a basis of (e)quality in institutions of higher learning, e.g. setting similar standards across borders as for example the Common European Framework of languages (Council of Europe 2001). As the majority of the world's population is multilingual and diversity of languages is the norm, the European Commission suggested a learning-friendly environment (community, schools, universities, workplace, at home) and offers lifelong learning programmes. A business forum for multilingualism has been set up in 2007, as language skills are becoming more and more important in the job market.

Aside from curriculum, funding and university rankings are becoming major factors that affect institutions of higher learning. Furthermore, in this context administrative work to be carried out by academicians increases, while pedagogy seems to be relegated to a secondary role (Koo, 2008), yet still a lot 
of wide-ranging research on pedagogical issues is mushrooming, constantly emphasising that learners are individuals and individuals are said to differ in their learning.

Definitions: For the purpose of this study, we do not extensively discuss diverse definitions of 'globalisation' and 'sustainability'. We follow the definition by Held (2000) who describes globalisation as 'a shift in the geography of local and global social relations' (Held 2000) and use the definition for sustainable development as addressed in the Brundtland Report (1987).

Sustainable development is development that meets the needs of the present without compromising the ability of future generations to meet their own needs.

Major aspects of sustainable development are outlined in a report by the Higher Education Funding Council for England, containing key points such as 'role of educators, generation and transfer of knowledge, leadership of and influence on, local, national and international networks, business strategy and operations' (HEFCE, 2005).

In our field of higher education it is time to consider how these perspectives are challenged and what education currently contributes to achieve sustainability, as done by Focht and Abramson (2009).

Situation of Germany and Malaysia: Economic developments, regional or global, require highly skilled people in various professional areas and universities play a vital role in order to 'generate' proficient and better workers. Combining educational and economic goals led to changes in teaching, research and the roles assigned to lecturers and students.

Time has come to re-assess or revise school curricula or academic curricular in order to ensure that the young generation will be able to cope with future demands of the changes in the 21st century in most aspects of life. In relating educational policies to demands of a globalised world and demographic changes, universities are forced to set new goals, to develop new programmes that can provide the knowledge and skills necessary to cope with future demands and to ensure a quality education for all. In nations already industrialized, e.g., Germany, structures of university systems undergo tremendous changes, whereas in countries like Malaysia, a rapid expansion of universities took place during the past two decades. The term 'education' unfortunately has a wide range of meanings in English, while its counterpart in German, 'Bildung', not really translatable, signifies a state of advanced - and general - knowledge. Maybe the lack of this target-term has lead to a partial disregard for its attainment?

Germany and Malaysia have close ties in various economical, technical and educational areas. In his special message the Vice Chancellor of USM (Universiti Sains Malaysia) addresses this relationship as follows.

As Malaysia aims to move into the group of highincome countries by the year 2020, Germany must be closely watched and emulated as a very successful innovative nation. Germany has shown the way to develop a sustainable environment very much in tandem to USM's vision of a sustainable tomorrow.

Germany serves as a model in the field of education and technology and a good number of Malaysian students have chosen Germany to further their studies, particularly in the field of science and engineering, as German universities offered study programmes different to those in other countries and were attributed with a high reputation.

Malaysia strives to become a regional hub for tertiary education and numerous efforts are undertaken to achieve this goal. One of the most emergent themes is to educate academically well-qualified graduates who are able to converse in more than one language. Other key concepts in the broader socio-political context of Malaysia are national development and internationalization which affect the educational landscape tremendously in terms of linguistic issues. Malaysia`s learning culture is still much dominated by testing and examination and some flawed assumptions of learning still exist. Standardization appears to be an equivalent for quality, not taking into account that human beings cannot be standardized. Standards are somewhat illusionary in the field of education and neglect the fluidity of all life and changes in the world. Thus, standardization and sustainability are opponents as standardization does not allow much space for developments. We may or may not agree that effort to standardize educational and pedagogical matters suffers from severe limitations in terms of sustainable development.

Current shifts in German tertiary education show a strong tendency towards homogenization and standardization, whereas in Malaysia voices become louder to shift away from a test-based learning environment, but paradoxically emphasizes ISO 9001 and other measurements to ensure quality. Present curricula do not really foster thinking skills (Lourdunathan and Menon, 2007), though subjects like Creative Thinking are taught. 
The traditional German System and its current transformations: In a nutshell, the traditional German university education was focusing on a (first) degree after 5 or more years of study after STPM respectively A-Level/Baccalaureate. No earlier qualifying examination was offered. Neither did anything similar to Bachelor or Masters Degrees exist. Thereby, the German university system differed from the British or American system and focused the attention on 'pure science'; undergraduate students are expected to elaborate and formulate scientific or academic opinions and have to carry out their studies in an independent manner. This generally resulted in longer studies at the university level and resulted in students delving further and deeper into fundamental, scientificrhetorical issues. Three major types of universities exist in Germany:

- Universities (Universitäten), comprising a huge variety of academic disciplines. The focus lies, according to the tradition, on research, theoretical orientations and research-oriented components

- Universities of Applied Sciences (Fachhochschulen), they concentrate on technical disciplines, engineering, business-related studies and design. The core of the studies has a professional character and usually includes internships or work in industry

- Colleges of Art/Music (Kunst-und Musikhochschulen) offer graduate studies for performing arts and music, in artistic and scientific fields follows:

Main types of classes have been structured as

- Lectures: The professor lectures on a given topic, students are expected to listen and to take notes and do additional reading

- Exercise classes: Students participate actively in discussing the subject matter

- Seminars: More advanced/in-depth knowledge is conveyed and discussed, seminars play an important role in the advanced stages

Important to note here is the Dual System, for which Germany used to be famous and highly appreciated globally; including the former Malaysian Prime Minister, Dr. Mahathir, who wanted to import this system into Malaysia by setting up the German Malaysian Institute (GMI). This dual system educated the school leavers who did not join the tertiary education institutions in so-called Berufsschulen (inadequately translatable to 'trade schools'). These schools prepare the students for specific crafts and trades, like banking, car repairmen, plumber, construction worker, et cetera. These programmes go on for 2-3 years, before the students become certified in their respective disciplines. A lot of the successes of the major German industries as global champions as exporters (Germany has been the largest exporter globally until 2009) are based on this dual system. It used to support the German successes by offering both: a largely non-commercially oriented research culture in the traditional universities providing a great number of fundamental research results; turned into commercial products by the developers in the industries that in turn are masterly made into physical products by the highly, practically qualified, leavers of the Berufsschulen.

Recently, the politicians and a group of businessoriented leaders in the universities have worked hard to convert the generally longer programmes, leading to degrees of Magister Artium or Diplom, respectively Staatsexamen (State Examination), to the global standard degrees of Bachelors and Masters.

Drastic shifts in higher education takes currently place within the framework of the Lisbon strategy and Bologna reforms. The process of implementing the new structure of first- and second level degree programmes (BA-, MA-programmes) will be completed in 2010 in order to ensure quality and comparability of qualifications and in order to provide students with skills and knowledge to be able to compete globally. So states the official line of reasoning, at least. More recently, fierce criticism of professors was raised and student protests against the Bachelor-reforms have taken place. A growing number of scholarly colleagues denote the reforms with "neuartige Dominanz geistfremder Kriterien" [novel dominance without mind] and a "technizistisch verengtes Konzept von Wissen, Bildung und Ausbildung im universitären Rahmen" [technocratic narrowed concepts of knowledge, nurturing and education within the universities]. Minor adjustments have been carried out; however, a returning to the unique German university system cannot be expected.

The Malaysian system and its changes: The university system in Malaysia, as based on the British system from colonial times (Malaysia was granted Independence in 1957), has always been based on the sequence of Bachelors and Masters degrees. The major transformation was the setting up of a huge number of new universities. At the time of independence, Malaysia had only 2 universities and only a decade ago, only a handful. In 2009, there are close to 30 public 
universities and a dozen of private universities. Most are based on technical and engineering subjects. Comparatively few programmes are offered in the social sciences. This goes very much in hand with the aspiration of Wawasan 2020, the vision of the former Prime Minister, Dr. Mahathir, to render Malaysia a fully developed economy by the year 2020. In accordance to current economic trends, the setting up of tertiary educational institutions to educate the necessary numbers of engineers, IT experts and developers, et cetera, is only a logical consequence.

It is therefore no surprise that Malaysia experiences ongoing reforms in curricular work that illustrate the move forward to a k- and an e-society. The importance of quality enhancement through implementing ISO 9001 et al is based on the hope that such measures provide students with the necessary skills and knowledge to achieve a high degree of professionalism and to produce graduates who meet the demands of the society.

It ought to be added, that Malaysia does not have a large number of qualified craftsmen, due to the lack of institutions like GMI in larger numbers. Therefore, it will not be able to service a market for small series, prototyping industries; it cannot compete in a market of turnkey projects. Its opportunities are based on its large population of generally well-educated factory workers and trades people.

We can postulate without reservation, that the Malaysian economy as based on manufacturing, massproduction essentially without added value, needs a great number of degree holders with specific qualifications, skills and abilities to foster and support the ongoing production processes. Therefore, the interventions of the Malaysian Qualifications Agency (MQA) and the Malaysian Qualifications Framework (MQF) to standardize the university programmes and courses in combination with a strict KPI to measure performance of teaching staff, supplement and support the needs of the industrial processes on which the prosperity of Malaysia are based.

Her main challenge is to gradually improve the R\&D-output to a level that allows to base manufacturing on home-grown instead of foreign intellectual property.

Common aspirations of Malaysia and Germany: In both countries, Malaysia and Germany, the target is that up to $50 \%$ of school graduates enrol in universities to achieve the intended goals to provide them with a basis for occupations or professions as the market dictates, as well as an elimination of social inequality. Current goals of higher education are similar in both countries, however, differences are existent, to begin with the education system which is highly centralized in Malaysia, but not in Germany due to its federalism and to end with a different tradition of learning culture, which is more exam oriented in Malaysia and to a lesser extent in Germany. Common features and orientations in higher institutions of learning are:

- Trends towards autonomy of schools and universities

- Lifelong learning

- Long-term sustainability, economically and ecologically

- Increasing numbers of university students

- Updating and modernizing curricula

- Making teaching and learning processes more efficient

- Quality orientation, evaluation

A paradigm shift of education is in process, influenced by cultural and economic issues. Reviewing the relevant literature, reports, as well as analysing core concepts of curricula, results in two observations about the current locus as well as directio.

Firstly, statements like:

- Developing understanding and the capacity to thrive is challenging and difficult and to do so successfully requires discipline, rigour and consistent effort (Bentley 1998)

- $\quad$ are hard to come across in the second half of the first decade of this new millennium. Is this concept outdated, not fashionable or simply not true?

Secondly, on the target fields of study, Spring (2007) comments, that:

- The decline of interest in social science instruction in favor of more math and science highlights the neglect or preparing students to participate in political, economic and social change. The primary goal of the human capital curriculum model is preparation for work in the global economy

- The declining interest in social sciences, philosophy. aesthetic education and literature in conjunction with a 'human capital agenda' limits the awareness of environmental and ecological issues, which are ironically parts of some curriculaas facts to be learned and examined

The sustainability of the educational systems in both countries: Having introduced the similarities and 
differences in both countries, we return to our initial objective: sustainability. Probably nobody will question that the current mainstream of shortened, well-certified and well-controlled delivery of content leads to improved employability of graduates, ready employability. As an example, the programme offered to the students in the courses of the co-author, foresees a certification in a vendor-specific database, certification as a networking expert offered by a specific vendor and more to come. Partially, vendoragnostic academic content has been replaced by vendor-provided delivery. No doubt, this increases the employability of the graduates. Though, again, the question arises if this can be married productively with the intentions of sustainability. It should be noticed that we lack evidence of whether those concepts mentioned above can contribute to sustainable development, even so it seems to be obvious that "lifelong learning", as example, contributes to sustainability. What about the historical idea of a university as imagined by Humboldt? What about the real purpose of lectures, which is "not the delivery of information, but the creation of an intellectual context" (Kramsch 2000)? Will the intellect be challenged and sharpened, which is a pre-condition for lifelong learning and sustainability? Although new curricula and concepts of university systems are characterised by innovativeness in the beginning of the 21st century, we have to critically view changes, developments and learning conditions. In line with Spivey (2007) we might agree that computer metaphors of the functioning of the human mind are inadequate, as the mind is steadily in flux and not a static product and mental processes are continuously dynamic. This is comparable to our world that is not composed of stable entities, but undergoes continuous changes. We might also pose the question whether linear conceptions of cause and effect followed by predictable consequences may be extrapolated over time, or create a foundation for sustainable developments. We rather support the idea of Valera et al. (1991) who say that "knowing how to negotiate our way through a world that is not fixed and pre-given but that is continually shaped by the types of actions in which we engage".

In our view, sustainable educational programmes are no static frames but provides affordances, based on Gibson (1979) theory of affordance which can be understood to develop an awareness of possibilities which particular situations provide. In the light of the foregoing we have to raise the question, if standardized measurements lend a suitable platform for sustainable education and lifelong learning programmes. Prescriptions and pro-scriptions may be useful in order to assess outcomes of learning; however, if affordances provided by any environment are not perceived by the learner, sustainability can hardly be achieved. Learners must be sensitized to environmental, social and educational information and must possess the capacity to deal with the challenges of the future world. Snow (1998) puts it this way.

A situation provides a suitable niche only for those persons who are prepared to meet and use its affordances effectively. Those not properly tuned or prepared will in some way fail to perform effectively in the situation as given.

Again, though, let us return to the objective of our undertaking here. Do current developments in both countries foster the needed underpinnings for a sustainable education?

New strategic goals: Promoting and implementing new strategic goals have become a core issue of higher education, not only in Malaysia and Germany, but in other parts of the world, too. This is one of the side effects of globalisation processes. As Spring (2007) puts it:

"Around the globe from China to Japan to the United States and the European Union, educational policy makers try to match the school curriculum and instruction to what they perceive are the needs of the global workplace [removed for clarity]. Is education only valuable for preparing students for employment? [removed for conciseness] Global schools are factories for processing raw human materials and approving them with tests and certificates to become global workers and consumers".

Following debates and discussions, the last two sentences express clearly the new paradigm of educational principles.

It remains to be seen, how far the 'instruction to being a globally employable workforce member' can be married to parallel aspirations of the $21^{\text {st }}$ century with respect to sustainability and highlighting and working towards the following targets and problems:

- Integrating sustainability principles into national planning

- Half the number of people without safe water by 2015

- Improvement of lives of slum dwellers by 2020 (Bruns et al., 2003)

Concepts: With particular reference to higher education, we focus on fundamental issues with regard to major shifts, essential needs, concepts and state education frameworks in light of social progress, 
economic demands and preparing students for the future. It becomes evident, that major goals of tertiary education do not differ much in various countries of today's globalised world, as students shall be prepared for an industrial consumer society (Munch, 2007). On the other hand, key elements of environmental issues, i.e. global warming, changing eco-systems and loss of natural resources have influenced curriculum designs in schools and universities. Concepts of a holistic education are much emphasized, however, there seems to be a paradox, as subjects of social sciences are on the decline, departments and faculties are closed and interest in 'soft' subjects exist to a lesser extent as interest in economics, business studies or subjects related to management studies. Discrepancies become obvious, as interrelations between economic growth and environmental damages exist to a certain extent. If sustainable development, as defined in the literature, emphasizes the importance of improving the quality of life on a global scale, we may critically ask whether goals, economic growth and awareness of living conditions without damaging natural resources or increasing them artificially, can be achieved in parallel. In Europe, in particular in Germany, the population is concerned with environmental and ecological issues, which is generally not the case in Malaysia. In academic settings, both countries strive to increase the number of graduates in order to produce the high skilled labor force of tomorrow and/or incorporate them into the mainstream society to the maximum possible. In denying differences of individuals, one dilemma becomes obvious: How can education offer equal chances for all, how do underprivileged become members of the elite and how can an equal education for all be achieved?

We may or may not agree with Henry (1994) who defends the idea that not everyone is pretty much alike and thus it would be illusionary to believe that each individual could achieve the same. Common sense may tell us that in areas like sports or music, talent plays a crucial role to play in the upper league in addition to hard work. Therefore we ask, whether innovative approaches in curricula, shifts in structures of universities and study goals as currently implemented, really help to overcome inequality and whether a sustainable education can be achieved at all and how.

Curricula-children of their time: Curricula are a product of their times, they are seldom a product of one single learning theory or single didactic concepts. Educational policy, ideology and political orientation as well as societal changes are most influencing factors when it comes to curriculum development.
Furthermore, curricula or parts of it are based in general on theories of education and learning theories. Thus, curricula are steadily revised according to the needs of the society and accompanying educational policies. Whilst in Germany achieving humanistic thinking as one of the major educational goals and philosophy formed the core of curricula at universities, the educational system was based on the essence of Humboldt's theories. Present-days curricula are more oriented towards persistent strives for innovation, management theories and organizational behavior, including key attributes as visions for the future, team management, relevant materials and not to forget the impact information technology has.

But curricula are not only children of their time, they are-as Karl Marx might have put it - as well children of the economic circumstances under which they are developed. As of today, it looks like they were devised under the supervision of industrial, moneyoriented circles.

Curricula have lost their exteriority to the industrial process. It remains to be seen, how far the hidden influence of multi-national conglomerates allows for educational systems to educate today the academics needed to advance and bring forth fundamentally new results in natural science, engineering and social sciences in 30 years from today.

Recently we encounter an increasing number of colleague Looi remarks in 2009 , as well as literature, that fundamental research is abandoned in formerly renown universities (e.g., Queensland University of Technology) completely, respectively in a significant decline (Dercourt, 2004).

We could continue by referring to some astounding results of research done for the World Bank, that show a lack of the implied correlation between advanced educational levels and higher income structures of the general population. Pritchett, for example, states that cross-national data show no association between increases in human capital attributable to the rising educational attainment of the labor force and the rate of growth of output per worker (Pritchett, 2001).

A cynic could pose the challenge to define the target field of the term 'sustainability' when used in the context of tertiary education. Does the term imply the sustainability of the progress that mankind has experienced in all fields in the last centuries and decades; in arts as well as in natural and social sciences? Or does it rather indicate the sustainability of the never-ending flux of industrially-suitably trained members of the workforce into the 
production processes, as filmed in Fritz Lang's movie 'Metropolis'?

\section{CONCLUSION}

We have outlined current trends that are increasingly determining the educational landscape.

We attempted to shed some light on the complexity of current issues in the field of education. We examined the ways that Germany and Malaysia take to cope with tertiary education in relation to market forces and found striking contradictions between study and practice. Practice trends in tertiary education in Germany and Malaysia show increasing trends to shift away from a sustainable education, if education, in a Humboldtian sense is to be understood to develop the individual and not to reduce the individual to a functionalist. This idea does not support a solipsistic world view but a thought of "selbsttätige Natur des Menschen" (loosely translatable to self-contained nature of a human). We do not deny that we have to go beyond conventional approaches when designing curricula, which are currently emphasizing competencies rather than content. Without fundamental knowledge (i.e. content) students will leave tertiary education without a thorough understanding of the content of the respective subject. McPeck (1981) argues, if one does not know much about nuclear physics, it would be difficult to think critically about the subject. We may agree with Mason (2008) that "the demands of the global economy which apparently needs active, creative and critical workers who are 'life-long' and 'life-wide' learners". However, we reserve to disagree with any potentially implied continuation to this thought that mangles curricula in a manner that steers education away from holistic to industry-specific targets and objectives.

On methodological issues: it might be forgotten, that no methodology will work if there is nothing to deliver. One can observe numerous so called innovative projects, encapsulated within curricular frameworks, which do not really challenge thinking processes. From our discussion it became quite clear, that current agendas frequently do not provide a real platform for sustainable education. Our intention was to provide the reader with some particular arguments and we hope to open a reflective discussion, as in our opinion the effectiveness of current curricula related to a sustainable development education has to be critically examined.

We are aware, though, that some flourishing projects with regard to sustainable education are effectively conducted worldwide. We hope that those efforts are leading to more awareness and foster a rethinking of predominant current practices and policies.

\section{REFERENCES}

Baker, C., 2001. Review of tove skutnabb-kangas linguistic genocide in education-or worldwide diversity and human rights. J. Sociolinguistics, 5: 279-283.

Bentley, T., 1998. Learning Beyond the Classroom. Education for a Changing World. 1st Edn., Routledge, USA., ISBN: 9780415182591, pp: 200.

Brundtland, G.H., 1987. Our Common Future: Report of the World Commission on Environment and Development. 1st Edn., Oxford University Press, Oxford, ISBN: 0-19-282080-X 1987, pp: 400.

Bruns, B., A. Mingat and R. Rakotomalala, 2003. Achieving Universal Primary Education by 2015: A Chance for Every Child. 1st Edn., The World Bank, Beijing, ISBN: 0-8213-5345-4 2003, pp: 254.

Council of Europe, 2001. Common European Framework of reference for Languages: Learning, Teaching, Assessment. 1st Edn., Cambridge University Press, Austraila, ISBN: 0-521-80313-6, pp: 260.

Dercourt, J. 2004. Les flux d'étudiants susceptibles d'accéder aux carrières de recherche: L'exemple de l'Ile-de-France dans le cadre national. 1st Edn., EDP Sciences, Germany, ISBN: 978-2-86883-7516, pp: 205.

Focht, W. and C.I. Abramson, 2009. The case for interdisciplinary environmental education and research. Am. J. Environ. Sci., 5: 124-129. DOI: 10.3844/.2009.124.129

Gibson, J.J., 1979. The Ecological Approach to Visual Perception. 2nd Edn., Houghton Mifflin, USA., ISBN: 0-8985-9959-8 1986, pp: 333.

HEFCE, 2005. Sustainable development in higher education. Higher Education Funding Council for England. http://www.hefce.ac.uk/pubs/hefce /2005/05_01/05_01.pdf

Held, D., 2000. A Globalizing World? Culture, Economics, Politics. 1st Edn., Routledge, USA., ISBN: 0-4152-2294-X 2000, pp: 188.

Henry, W.A., 1994. In Defence of Elitism. 1st Edn., Anchor Books, USA., ISBN: 978-0385479431 1994, pp: 212.

Koo, Y.L., 2008. Language, Culture and Literacy: Meaning-making in Global Contexts. 1st Edn., University Kebangsaan Malaysia, Malaysia, ISBN: 987-983-9391-46-6 2008, pp: 139. 
Kramsch, C., 2000. Statement of Teaching Philosophy. Berkley. University of California. http://teaching.berkeley.edu/dta00/kramsch.html

Lourdunathan, J. and S. Menon, 2007. Mapping the Route to a Thinking Curriculum. ELT Matters 3. Developments in English Language Learning and Teaching, Mukundan, J., S. Menon and A.A. Hussin (Eds.). University Putra Malaysia Press, Serdang, pp: 118-124.

Maley, A., 2007. Swimming Against the Tide. ELT Matters 3. In: Developments in English Language Learning and Teaching, Mukundan, J., S. Menon and A. A. Hussin (Eds.). University Putra Malaysia Press, Serdang, pp: 22-33.

Mason, M., 2008. Critical Thinking and Learning. In: Critical Thinking and Learning, Mason, M. and M. Mason (Eds.). Blackwell, Malden, pp: 1-11.

McPeck, J., 1981. Critical Thinking in Education. 1st Edn., Martin Robertson, ISBN: 978-0855203832, pp: 170.

Mufwene, S.S., 2008. Language Evolution. Contact, Competition and Change. 1st Edn., Continuum, USA., ISBN: 978-0826493705, pp: 376.

Munch, R., 2007. Akademischer Kapitalismus. Die Zeit, 40: 67-67.

Pritchett, L., 2001. Where has all the education gone? World Bank Econ. Rev., 15: 367-391. DOI: 10.1093/wber/15.3.367
Snow, R.E., 1998. Abilities as Aptitudes and Achievements in Learning Situations. In: Human Cognitive Abilities, McArdle, J.J. and R.W. Woodcock (Eds.). Lawrence Erlbaum Associates, Mahwah, NJ., pp: 93-112.

Spivey, M., 2007. The Continuity of Mind. 1st Edn., Oxford University Press, Oxford, ISBN: 9780195170788, pp: 428.

Spring, J., 2007. A New Paradigm for Global School Systems. Education for a Long and Happy Life. 1st Edn., Routledge, USA., ISBN: 9780805861235 2007, pp: 215.

Varela, F.J., E. Thompson and E. Rosch, 1991. The Embodied Mind: Cognitive Science and Human Experience. 1st Edn., MIT Press, USA., ISBN: 978-0262720212, pp: 308.

Waldinger, R. and Michael I. Lichter, 2003. How the Other Half Works. Immigration and the Social Organization of Labor. 1st Edn., University of California Press, USA., ISBN: 9780520231627, pp: 285.

Wolf, A., 2002. Does Education Matter? Myths about Education and Economic Growth. 1st Edn., Penguin Books, UK., ISBN: 978-0140286601, pp: 352. 